\title{
Pyramiding insect and disease resistance in an elite indica rice cultivar asd16
}

\author{
T. RAJESH ${ }^{1 *}$, S. MARUTHASALAM ${ }^{1}$, K. KALPANA ${ }^{1}$, K. POOVANNAN ${ }^{1}$, K.K. KUMAR ${ }^{1}$, \\ E. KOKILADEVI ${ }^{1}$, D. SUDHAKAR ${ }^{1}$, R. VELAZHAHAN ${ }^{2}$, and P. BALASUBRAMANIAN ${ }^{1}$
}

Department of Plant Molecular Biology and Bio-Technology, Center for Plant Molecular Biology, Tamil Nadu Agricultural University, Coimbatore 641003, Tamil Nadu, Indial Department of Plant Pathology, Center for Plant Protection Studies, Tamil Nadu Agricultural University, Coimbatore 641003, Tamil Nadu, India ${ }^{2}$

\begin{abstract}
Pyramiding transgenes of interest is one of the strategies to engineer multiple stress resistance in crop plants. Transgenic plants which stably express different genes can be hybridized to bring these genes together in one plant. Transgenic rice (Oryza sativa L. cv. ASD 16) plants harbouring genes Xa21 (conferring bacterial blight resistance), tlp (conferring resistance to sheath blight), or gna (conferring resistance to brown planthopper) were used in hybridization experiments. Sexual hybridization was carried out in two different gene combinations: Xa21 $\times$ gna and tlp $\times$ gna. Molecular analyses were carried out to confirm the presence of transgenes. In $\mathrm{F}_{1}$ generation, lines harbouring either gene in each of the crosscombination were selected and forwarded to $\mathrm{F}_{2}$ generation. The presence of genes in $\mathrm{F}_{2}$ generation was confirmed by PCR, Southern blot hybridization, and Western blotting. The $\mathrm{F}_{2}$ progeneis harbouring Xa21 and gna exhibited resistance against bacterial blight and moderate resistance against brown planthopper. Similarly, the $\mathrm{F}_{2}$ lines of tlp and gna combination provided resistance against sheath blight and moderate resistance against brown planthopper. The level of resistance observed in pyramided lines for insect or pathogens was comparable to the resistance observed in their parental lines. Our study shows that pyramiding genes by hybridization between transgenic plants could be one of the strategies to develop cultivars with multiple biotic stress resistances.
\end{abstract}

Additional key words: bacterial blight, brown planthopper, gna, Oryza sativa, sheath blight, tlp, Xa21.

\section{Introduction}

Rice (Oryza sativa L.) is a staple food for more than half of the world's population and is one of the three major food crops (Mohanty 2013). Biotic stresses including diseases, insects, and weeds are serious constraints to rice production. Among various diseases infecting rice, bacterial blight (BB) caused by Xanthomonas oryzae pv. oryzae (Uyeda and Ishiyama) Dowson and sheath blight (ShB) caused by Rhizoctonia solani Kuhn are serious ones. Brown planthopper (BPH) (Nilaparvarta lugens Stal.) is a major sucking pest of rice. As the demand for rice is on the increase, there is a need to improve the productivity of crop by managing factors that influence yield. Rice yield losses caused by BB in severe cases can reach up to
$50 \%$ when plants are infected at the maximum tillering stage (Datta et al. 2002). The Xa21, a dominant gene for resistance to $\mathrm{BB}$ was transferred from a wild species, Oryza longistaminata, to cultivar IR24 by back crossing (Khush et al. 1990). Ronald et al. (1992) isolated Xa21 by positional cloning. Transfer of this gene into the genome of an elite indica rice cultivar IR72 and field evaluation has been carried out by Tu et al. (2000). The hybrid rice plants with $\mathrm{Xa2} 1$ displayed high broad spectrum resistance to Xanthomonas oryzae pv. oryzae (Xoo) races besides maintaining agronomic performance (Zhai et al. 2001). $\mathrm{BB}$ resistant indica rice lines of ASD16, PB1, ADT38, and White Ponni engineered with $\mathrm{Xa} 21$ following particle bombardment method of transformation were developed by our group (Maruthasalam et al. 2007). Baliyan et al.

Submitted 29 April 2019, last revision 3 July 2019, accepted 19 August 2019.

Abbreviations: BB - bacterial blight; ShB - sheath blight; BPH - brown planthopper; HRLH\% - highest relative lesion height percentage; PR - pathogenesis related; TLP - thaumatin-like proteins; Xoo - Xanthomonas oryzae pv. oryzae

Acknowledgements: The authors are grateful to the Rockefeller Foundation, USA [\# 99001/225 (PB) and \# 99001/227 (DS)] and the Department of Biotechnology, New Delhi, India, for providing the financial support. We greatly acknowledge the help provided by Dr. Legrand, Strasbourg, France and Dr. S.S. Muthukrishnan, Kansas State University, Manhattan, USA.

* The corresponding author's present address: School of Crop Protection, College of Post Graduate Studies in Agricultural Sciences, Central Agricultural University, Umiam 793103, Meghalaya, India; e-mail: agripathrajesh@rediffmail.com 
(2016) demonstrated higher resistance against BB in pyramided rice genotype CSR-30 harbouring three genes ( $x a 5, x a 13$, and $X a 21)$ than in lines expressing single or two genes. Similarly, marker assisted transfer of Xa21 and Xa33 into an elite line of rice DRR17B showed high BB resistance without compromising the agro-morphological attributes of parental lines (Balachiranjeevi et al. 2018).

The ShB of rice caused by soil borne fungus Rhizoctonia solani Kuhn [teleomorph stage, Thanatephorus cucumeris (Frank) Donk], is a dreadful disease in many rice growing areas of the world. Yield loss ranges from 8 to $50 \%$, particularly when the infection is severe (Savary et al. 2000). Among different pathogenesis related (PR)-proteins, chitinases (PR-3 proteins) and thaumatin-like proteins (TLP; PR-5 proteins) have been employed effectively to engineer ShB resistance in elite rice cultivars, worldwide. Several TLPs were isolated and cloned from plant species including maize (Roberts and Selitrennikoff 1990), bean (Sehgal et al. 1991), sorghum, oat (Vigers et al. 1991), wheat (Rebmann et al. 1991), and rice (Velazhahan et al. 1998). Plants with high expression of TLP were shown to be resistant to the ShB pathogen (Datta et al. 1999). The indica rice cvs. PB1, ASD16, and White Ponni which were engineered with tlp in our laboratory through biolistic mode of transformation showed enhanced resistance against ShB pathogen, $R$. solani (Maruthasalam et al. 2007). In recent studies, combinations of defence genes always showed stronger and durable resistance to fungal and/or bacterial pathogen(s) than those lines expressing single gene (Fukuoka et al. 2015, Yasuda et al. 2015, Arunakumari et al. 2016). Gene pyramiding not only extends the durability of resistance but also enhances the spectrum of resistance.

Rice BPH (Nilaparvarta lugens Stal.) belonging to the order Homoptera is one of the major insect pests of rice causing huge crop loss (Khush et al. 1990). ВPH causes direct physiological damage to rice by the removal of phloem sap and blockage of phloem vessels leading to hopper burn (Ou 1985). Plant lectins were shown to produce chronic effects on survival and development of insect pests belonging to different insect orders (Czapla and Lang 1990, Habibi et al. 1993, Powell et al. 1993, 1995). The snowdrop lectin (Galanthus nivalis agglutinin: GNA) is the most toxic of the lectins tested, decreasing BPH survival by $50 \%$ at concentrations as low as $6 \mu \mathrm{M}$ (Powell et al. 1995). Bioassays carried out in transgenic rice plants expressing gna indicated that the GNA is effective in decreasing survival, development and fecundity in $\mathrm{BPH}$ (Rao et al. 1998).

One of the major objectives of rice biotechnology programmes is to pyramid genes with a view to imparting multiple stress resistance. Only a few reports are available on transgenic lines carrying genes effective against more than one taxa of pathogen or insect pest. The simultaneous introduction of three insecticidal genes (the $B t$ genes, $c r y l A c$, and $c r y 2 A$ and the snowdrop lectin gene, gna) into commercially important indica rice cultivars by particle bombardment for broad spectrum resistance against different rice pests: leaffolder (Cnaphalocrocis medinalis) yellow stemborer (YSB, Scirpophaga incertulas) and
BPH was reported by Maqbool et al. (2001). Transgenepyramided stable rice lines resistant to disease and insect pests were developed by conventional crossing of two transgenic parental lines transformed independently with different genes. IR72 engineered with a rice chitinase $(R C 7)$ gene (for $\mathrm{ShB}$ resistance), $\mathrm{Xa21}$ (for $\mathrm{BB}$ resistance) and the $B t$ fusion gene (for insect resistance) were developed by reciprocal crossing of two transgenic homozygous IR72 lines (Datta et al. 2002). The BB resistance gene, Xa21 and a $B t$ fusion gene crylAb/crylAc conferring insect resistance were pyramided into Minghui 63 by marker assisted selection. The pyramided line and its derived hybrids show high resistance against leaffolder, YSB, and BB (Jiang et al. 2004). Breeding of transgenic restorer line for multiple resistance against BB, striped stem borer and herbicide tolerance was developed by conventional crossing of two stable transgenic rice lines: Zhongguo91 with $c r y 1 A b$ and bar genes and Yujing6 with $X a 21$ gene (Wei et al. 2008). These approaches maximize the utility of gene transfer technology to introduce combination of different genes into rice providing a multi-mechanism defence.

Although several reports are available on rice transformation using single genes of interest, only a few reports are available on gene pyramiding in rice against both insect and disease. This urges the need for developing multiple resistance rice lines to effectively combat multiple biotic stresses. The present study was carried out to develop lines with multiple resistance to insect $(\mathrm{BPH})$ and diseases (BB or ShB) in an elite local rice cultivar ASD16 by employing conventional crossing between transgenic events homozygous for transgenes.

\section{Materials and methods}

Generation of pyramided lines: Sexual hybridization of homozygous transgenic rice (Oryza sativa L.) lines were done in our laboratory earlier and $\mathrm{X}_{1}$ and $\mathrm{X}_{2}$ (two homozygous Xa21 lines conferring BB resistance), $\mathrm{T}_{1}$ and $\mathrm{T}_{2}$ (two homozygous tlp lines governing ShB resistance) and $\mathrm{G}$ (a homozygous gna line expressing BPH resistance) were grown in the transgenic greenhouse at Tamil Nadu Agricultural University, Coimbatore, India.

The homozygosity was confirmed by PCR and Western blotting. Two different crosses, Xa21 $\times$ gna and tlp $\times$ gna were performed. After the sexual hybridization, $\mathrm{F}_{1}$ hybrid seeds were collected at maturity for further studies. $F_{1}$ progeny of the different cross-combinations were forwarded to $F_{2}$ generation after confirming expression of both the genes (Xa21 and gna or tlp and gna). The resulting $\mathrm{F}_{2}$ progenies were named $\mathrm{X}_{1} \mathrm{G}$ and $\mathrm{X}_{2} \mathrm{G}$ $(X a 21 \times g n a)$ and $\mathrm{T}_{1} \mathrm{G}$ and $\mathrm{T}_{2} \mathrm{G}($ tlp $\times$ gna $)$ according to the gene combinations.

Southern blot hybridization analysis: The parental homozygous ASD16 lines and their selected $\mathrm{F}_{2}$ lines were analyzed by Southern blot hybridization. The genomic DNA $(10 \mu \mathrm{g})$ extracted from transgenic plants and nontransgenic control plants and $5 \mathrm{ng}$ of plasmid DNAs 
(positive control) were digested overnight with appropriate restriction endonucleases (Bangalore Genei, Bangalore, India). The products were electrophoresed on $1.0 \%(\mathrm{~m} / \mathrm{v})$ agarose gels and then transferred onto nylon membranes (Hybond ${ }^{+}$, Boehringer, Mannheim, UK). The blots were subsequently hybridized overnight with radiolabelled probes prepared by random primer oligo labelling method (Random Primer Labeling kit, Bangalore Genei).

To confirm the presence of Xa21, the genomic DNA isolated from $\mathrm{F}_{2}$ progenies and their parental lines were digested with EcoRV to release a $3.8 \mathrm{kbp}$ (containing most of the coding sequence of the Xa21; Wang et al. 1996) internal fragment of Xa21 (9.6 kbp) and hybridized with $\alpha{ }^{-32} \mathrm{P}$ dCTP-labeled $3.8 \mathrm{kbp} X a 21$ coding sequence obtained by digesting pC822 with EcoRV. To confirm the presence of tlp gene, the genomic DNA were digested with HindIII to release the $3.1 \mathrm{kbp}$ TLP expression cassette and hybridized with $\alpha-{ }^{32} \mathrm{P}$ dCTP-labeled $1.1 \mathrm{kbp}$ TLP coding sequence. Similarly, the genomic DNA were digested with $K p n I$ to release the 480 bp gna expression cassette and blotted onto the membrane with a view to demonstrating the presence of gna gene. The blot was then probed with $\alpha-{ }^{32} \mathrm{P}-\mathrm{dCTP}$-labelled $5.0 \mathrm{~kb}$ fragment obtained by digesting pubi-gna with KpnI enzyme.

Bioassay experiments: Bioassays for $\mathrm{BB}$ and $\mathrm{BPH}$ were performed in two $\mathrm{F}_{2}$ lines carrying both Xa21 and gna genes. Similarly, bioassays for ShB and BPH were carried out in two $\mathrm{F}_{2}$ lines harbouring both tlp and gna genes. In all the experiments, $F_{2}$ lines, parental homozygous lines, and non-transformed control plants were used. All the bioassay experiments were repeated thrice under the same conditions to confirm the resistance.

A virulent isolate of Xoo (Directorate of Rice Research, Hyderabad, India) maintained on peptone sucrose agar (PSA; $5.0 \mathrm{~g} \mathrm{dm}^{-3}$ peptone, $20.0 \mathrm{~g} \mathrm{dm}^{-3}$ sucrose, $0.5 \mathrm{~g} \mathrm{dm}^{-3}$ $\mathrm{Ca}\left(\mathrm{NO}_{3}\right)_{2} \cdot 4 \mathrm{H}_{2} \mathrm{O}, 0.5 \mathrm{~g} \mathrm{dm}^{-3} \mathrm{FeSO}_{4} .7 \mathrm{H}_{2} \mathrm{O}, 2.0 \mathrm{~g} \mathrm{dm}^{-3}$ $\mathrm{Na}_{2} \mathrm{HPO}_{4} \cdot 2 \mathrm{H}_{2} \mathrm{O}, 20.0 \mathrm{~g} \mathrm{dm}^{-3}$ agar) was used as source of inoculum. A loopful of bacteria was streaked onto a PSA slant and allowed to grow for $48 \mathrm{~h}$ at $28^{\circ} \mathrm{C}$. Bacterial suspension was prepared by adding sterile distilled water $\left(10 \mathrm{~cm}^{3}\right)$ into the 48 -h-old culture and adjusting bacterial population to $10^{9}$ cells $\mathrm{cm}^{-3}$. All inoculations were made within 30 - 60 min after preparing the bacterial suspension.

The parental homozygous Xa21 lines along with their $\mathrm{F}_{2}$ derivatives (expressing Xa21 and gna) maintained in a greenhouse for transgenic plants were evaluated for BB resistance. Leaf clipping method (Kauffman et al. 1973) was employed for inoculating 60- to 80-d-old plants at maximum tillering stage. After inoculation, the plants were covered with polyethylene bags with inner surface sprinkled with sterile distilled water to maintain plants under high relative humidity for better symptom development. From each line, five plants (5 - 10 leaves per plant) were inoculated along with suitable non-transgenic control plants. Lesion length was measured $14 \mathrm{~d}$ after inoculation and based on the length of the developed lesions, the plants were categorized as resistant $(1-3 \mathrm{~cm})$, moderately resistant $(3-6 \mathrm{~cm})$, and susceptible $(>9 \mathrm{~cm})$, as described by Mew and Vera Cruz (1979).
The parental homozygous tlp lines with their $\mathrm{F}_{2}$ derivatives (expressing tlp and gna) were evaluated for ShB resistance along with suitable non-transgenic control plants. Two different ShB assay methods, one using detached leaves and another with intact leaf sheaths, were employed for screening the transgenic line, as described by Kumar et al. (2003). All the inoculations were carried out with $5 \mathrm{~mm}$ mycelial discs obtained from 3-d-old Rs7 (a virulent isolate of $R$. solani; Krishnamurthy et al. 1999) maintained on potato dextrose agar $\left(250.0 \mathrm{~g} \mathrm{dm}^{-3}\right.$ potato, $20.0 \mathrm{~g} \mathrm{dm}^{-3}$ dextrose, $20.0 \mathrm{~g} \mathrm{dm}^{-3}$ agar, $\mathrm{pH} 7.0$ ).

In bioassay using detached leaves, observations were made at 24-h intervals and infection cushions were counted under a stereo microscope, $72 \mathrm{~h}$ after inoculation (HAI). In bioassay using intact leaf sheaths, observations were made up to $7 \mathrm{~d}$ at 24-h intervals. At $168 \mathrm{HAI}$, the highest relative lesion height percentage (HRLH\%) and the total lesion spread were estimated. HRLH\% was calculated as: HRLH $\%=($ length of the highest lesion / plant height $) \times$ 100.

For screening BPH resistance, standard seedling box screening test described by Heinrich and Mochida (1984) was followed. Parental transgenic homozygous gna line and four $\mathrm{F}_{2}$ lines (expressing Xa21 and gna or tlp and gna) along with a non-transgenic ASD16 control were used. Each transgenic line was sown in a row of the seed box (approximately 25 seeds/row). Simultaneously, one row of a susceptible check, TN1 and one row of a resistant check, PTB33 were also sown at random in seedling box. The BPH population cultured on TN1 plants was used to infest the seedlings. The seedlings were infested $14 \mathrm{~d}$ after sowing (DAS) with second and third instar nymphs. The plants with nymphs were gently tapped over the seedlings in such a way that approximately 4 - 5 nymphs settle on each seedling. Three replications (5 - 10 seedlings per replication) were maintained for each line. After the infestation, the lines were observed regularly for BPH damage symptoms. When the seedlings of the susceptible check were about $90 \%$ dead, the test lines were examined and each seedling was given a score of 1 (= very slight damage) to 9 (= all plants dead) as per the damage scales of the Standard Evaluation System for rice (IRRI 1988).

Statistical analyses: All the bioassay experiments were carried out in completely randomized design with adequate replications. Duncan's multiple range test (DMRT; Gomez and Gomez 1984) was used to compare treatment means using the software IRRISTAT v. 3.1 (International Rice Research Institute, Manila, The Philippines).

\section{Results}

During Southern blotting analysis, EcoRV fragment of pC822, hybridization signal of $3.8 \mathrm{kbp}$ was detected in the blots probed with the $3.8 \mathrm{kbp}$ in parental lines, $\mathrm{X}_{1}$, $\mathrm{X}_{2}$, and $\mathrm{F}_{2}$ lines, $\mathrm{X}_{1} \mathrm{G}$ and $\mathrm{X}_{2} \mathrm{G}$. In addition to this, a high molecular mass band was observed in all the transgenic lines including non-transgenic control (Fig. 1). The banding pattern of parental lines and the corresponding 


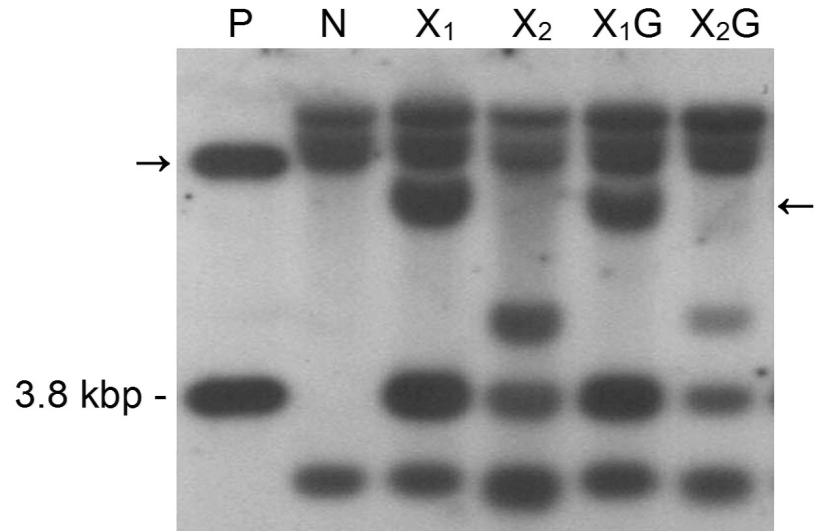

Fig. 1. Southern blotting analysis of the Xa21 gene in parental ASD16 and $F_{2}$ lines. The $3.8 \mathrm{kbp}$ band indicates the stable integration of the Xa21 gene in their genomes, and arrows indicate possible hybridization to the polymorphic member of the Xa21 gene family. Lane $P$ - positive control (pC822 digested with EcoRV), lane $N$ - non-transgenic control, lanes $X_{l}$ and $X 2$ - transgenic ASD16 lines harbouring the Xa21 gene, lanes $X_{l} G$ and $X_{2} G$ - transgenic lines harbouring both $X a 21$ and gna genes.

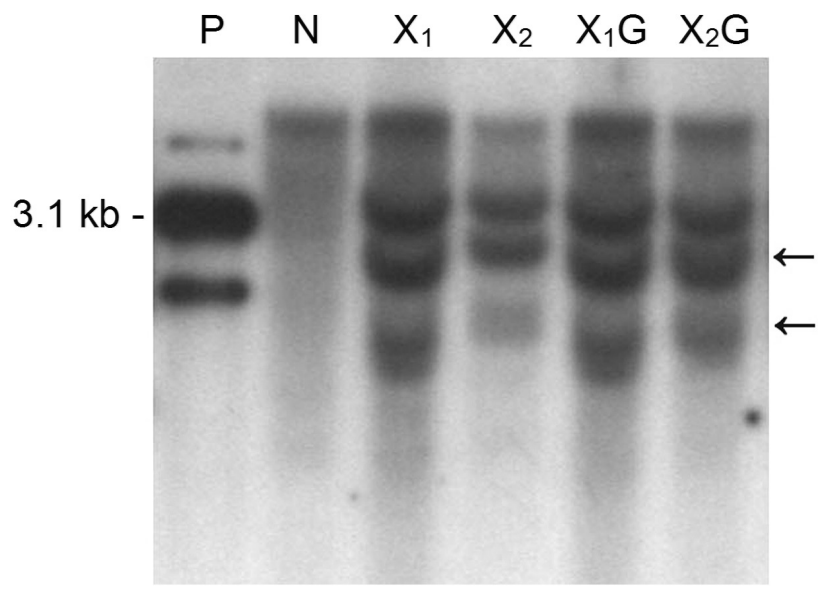

Fig. 2. Southern blotting analysis of tlp in parental ASD16 and $\mathrm{F}_{2}$ lines. The $3.1 \mathrm{kbp}$ band indicates the stable integration of TLP expression cassette $(3.1 \mathrm{kbp})$ in their genomes, and arrows indicate possible hybridization to the endogene with sequence homology to the introduced (tlp) gene. Lane $P$ - positive control (pGL2 digested with HinDIII), lane $N$ - non-transgenic control, lanes $T_{l}$ and $T 2$ - transgenic lines harbouring tlp gene, lanes $T_{l} G$ and $T_{2} G$ - transgenic lines harbouring both tlp and gna genes.

$\mathrm{F}_{2}$ progeny lines were found to be similar indicating the stable integration and inheritance of $X a 21$. The blot with genomic DNA of $\mathrm{F}_{2}$ progenies of lines harbouring tlp and gna, when probed with $1.1 \mathrm{kbp}$ tlp coding sequence, showed a $3.1 \mathrm{kbp}$ hybridization signal in two independent parental lines, $T_{1}, T_{2}$, and two $F_{2}$ lines, $T_{1} G$ and $T_{2} G$ (Fig. 2). When transgenic $\mathrm{F}_{2}$ progenies harbouring Xa21 and gna were subjected to Southern hybridization, $\alpha-{ }^{32} \mathrm{P}$-dCTP-labeled gna detected a $480 \mathrm{bp}$ band in the parental line $G$ and corresponding $F_{2}$ lines, $X_{1} G, X_{2} G, T T_{1} G$, and $T_{2} G$ revealing the stable integration and inheritance of

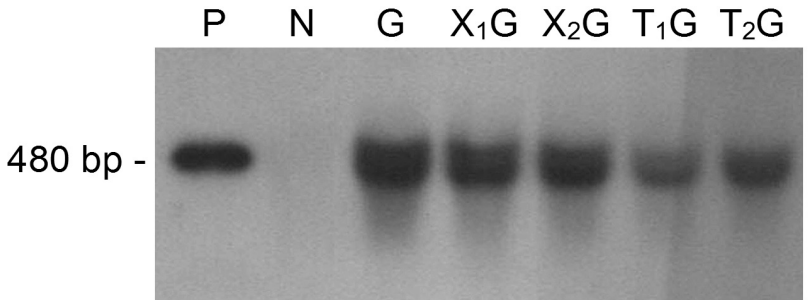

Fig. 3. Southern blotting analysis of gna in parental ASD16 and $\mathrm{F}_{2}$ lines. The $480 \mathrm{bp}$ band indicates the stable integration of gna expression cassette $(3.1 \mathrm{kbp})$ in their genome. Lane $P$ - positive control (pubi-gna digested with KpnI), lane $N$ - non-transgenic control, lane $G$ - transgenic ASD16 lines harbouring gna gene, lanes $X_{1} G$ and $X_{2} G$ - transgenic lines harbouring both Xa21 and gna genes, lanes $T_{1} G$ and $T_{2} G$ - transgenic lines harbouring both tlp and gna genes.

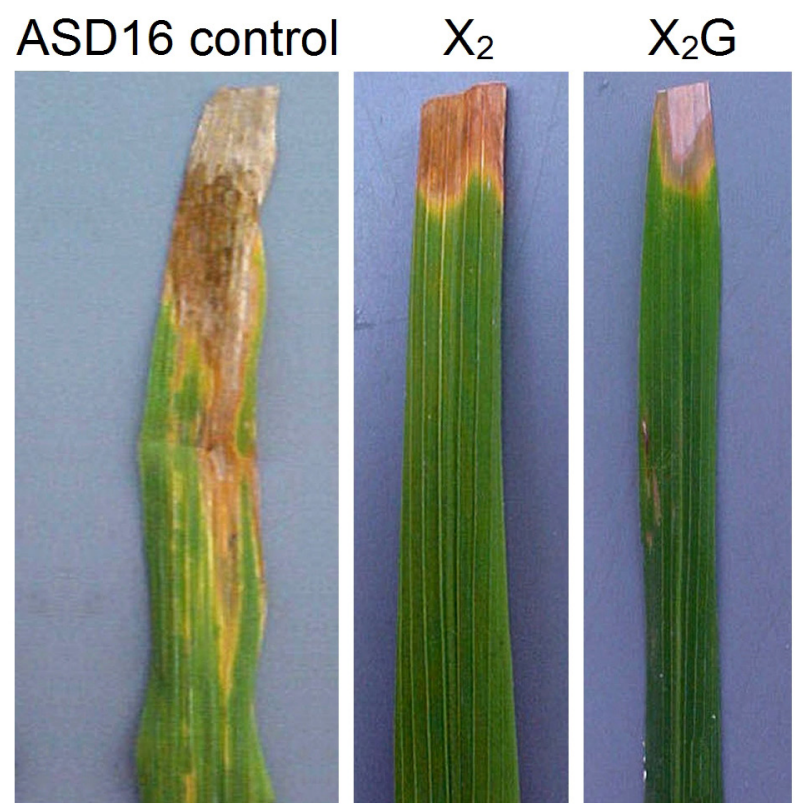

Fig. 4. Assessment of bacterial blight resistance by leaf clipping method in the parental ASD16 line and its $\mathrm{F}_{2}$ progeny expressing the $\mathrm{Xa21}$ gene.

gna expression cassette in their genomes (Fig. 3).

The BB symptom initiated within $4-5 \mathrm{~d}$ after inoculation in both transgenic (parental lines and $\mathrm{F}_{2}$ lines) and ASD16 control plants. Initially water-soaked lesions developed from the cut surface which spread along the veins of the inoculated leaf presenting a yellowish lesion with wavy margins (Fig. 4). However, on day 14 after inoculation, lesion length on non-transgenic ASD16 plants registered $17.07 \mathrm{~cm}$, whereas in one of the parental lines, $\mathrm{X}_{2}$ and it's $\mathrm{F}_{2}$ progeny, $\mathrm{X}_{2} \mathrm{G}$, the lesion length was restricted to 2.31 and $2.55 \mathrm{~cm}$, respectively (Fig. 4, Table_1). An another parental line, $X_{1}$ and it's $F_{2}$ progeny, $X_{1} G$ also recorded relatively lesser lesion length of 2.80 and 2.87 .cm respectively (Table 1).

In bioassay of ShB using detached leaves, the pathogen induced formation of infection cushions away from the 
Table 1. Bioassay of parental $\mathrm{Xa} 21$ lines and their $\mathrm{F}_{2}$ progenies for resistance to Xanthomonas oryzae pv. oryzae. Means of five replications (5-10 leaves/replication). Lesion lengths: $1-3 \mathrm{~cm}$ (resistant), $3-6 \mathrm{~cm}$ (moderately resistant), $>9 \mathrm{~cm}$ (susceptible). Means followed by different letters are significantly different at $5 \%$ level by the Duncan's multiple range test.

\begin{tabular}{lcl}
\hline Line & Lesion length $[\mathrm{cm}]$ & Disease reaction \\
\hline $\mathrm{X}_{1}$ (parent) & $2.80^{\mathrm{c}}$ & resistant \\
$\mathrm{X}_{2}$ (parent) & $2.31^{\mathrm{a}}$ & resistant \\
$\mathrm{X}_{1} \mathrm{G}$ & $2.87^{\mathrm{d}}$ & resistant \\
$\mathrm{X}_{2} \mathrm{G}$ & $2.55^{\mathrm{b}}$ & resistant \\
ASD16 control & $17.07^{\mathrm{e}}$ & susceptible \\
\hline
\end{tabular}

Table 2. Assessment of sheath blight resistance in parental tlp lines and their $F_{2}$ progenies by detached leaf assay. Means of three replications (three leaf bits/replication). Means followed by different letters are significantly different at $5 \%$ level by the Duncan's multiple range test.

\begin{tabular}{ll}
\hline Line & Number of infection cushions \\
\hline $\mathrm{T}_{1}$ (parent) & $15.20^{\mathrm{a}}$ \\
$\mathrm{T}_{2}$ (parent) & $16.40^{\mathrm{c}}$ \\
$\mathrm{T}_{1} \mathrm{G}$ & $15.90^{\mathrm{b}}$ \\
$\mathrm{T}_{2} \mathrm{G}$ & $16.90^{\mathrm{d}}$ \\
ASD16 control & $47.80^{\mathrm{e}}$ \\
\hline
\end{tabular}

site of inoculation by putting forth new hyphae occurred 48 HAI in both transgenic and non-transgenic plants. However, the frequency of formation of infection cushions in non-transgenic ASD16 was 47.8, while it was only 15.2 in $T_{1}, 16.4$ in $T_{2}, 15.9$ in $T_{1} G$, and 16.9 in $T_{2} G$ (Table 2). Moreover, in all transgenic lines, small brownish lesions (3- $5 \mathrm{~mm}$ diameter) were formed at the site of infection cushion formation at 48 - $72 \mathrm{HAI}$, while the inoculated leaves remained green and fresh. However, in nontransgenic ASD16 leaves, lesions $(1.5-2.0 \mathrm{~cm})$ with brown margins and grey centre were formed at the site of infection cushion formation. These lesions gradually enlarged in size covering almost the entire length of the leaf
Table 3. Assessment of sheath blighting using highest relative lesion height percentage (HRLH\%) and total lesion spread in the parental tlp lines and their $\mathrm{F}_{2}$ progenies. Means of three replications (three tillers/replication). Means followed by different letters are significantly different at $5 \%$ level by the Duncan's multiple range test.

\begin{tabular}{lll}
\hline Line & HRLH\% & Total lesion spread $[\mathrm{cm}]$ \\
\hline SM-ASD16-1-3-2 (parent) & $2.34^{\mathrm{b}}$ & $4.91^{\mathrm{b}}$ \\
KL-ASD16-2-1-5 (parent) & $2.66^{\mathrm{c}}$ & $6.74^{\mathrm{d}}$ \\
$\mathrm{T}_{1} \mathrm{G}$ & $2.15^{\mathrm{a}}$ & $4.47^{\mathrm{a}}$ \\
$\mathrm{T}_{2} \mathrm{G}$ & $2.76^{\mathrm{d}}$ & $6.25^{\mathrm{c}}$ \\
ASD16 control & $8.40^{\mathrm{e}}$ & $11.83^{\mathrm{e}}$ \\
\hline
\end{tabular}

Table 4. Bioassay of the $\mathrm{F}_{2}$ progenies of $g$ na for brown planthopper resistance. Means of three replications (5 - 10 seedlings per replication). Damage rating: 1 - 3 (resistant), 3 - 5 (moderately resistant), 5 - 7 (susceptible), 7 - 9 (highly susceptible). Means followed by different lettesr are significantly different at $5 \%$ level by the Duncan's multiple range test.

\begin{tabular}{|c|c|c|}
\hline Line & Damage rating & Insect reaction \\
\hline G & $4.90^{\mathrm{e}}$ & moderately resistant \\
\hline $\mathrm{X}_{1} \mathrm{G}$ & $4.40^{\mathrm{b}}$ & moderately resistant \\
\hline $\mathrm{X}_{2} \mathrm{G}$ & $4.80^{\mathrm{d}}$ & moderately resistant \\
\hline $\mathrm{T}_{1} \mathrm{G}$ & $4.70^{\mathrm{c}}$ & moderately resistant \\
\hline $\mathrm{T}_{2} \mathrm{G}$ & $5.60^{\mathrm{f}}$ & susceptible \\
\hline ASD16 control & $7.70^{\mathrm{g}}$ & highly susceptible \\
\hline PTB33 (resistant check) & $2.80^{\mathrm{a}}$ & resistant \\
\hline TN1 (susceptible check) & $8.60^{\mathrm{h}}$ & highly susceptible \\
\hline
\end{tabular}

leading to yellowing and drying within 72 HAI (Fig. 5).

In intact leaf sheath assay, the HRLH $\%$ and total lesion spread were the factors used to study the relative resistance/susceptibility of transgenic and non-transgenic lines for sheath blighting. In transgenic parental and $\mathrm{F}_{2}$ lines, no lesions appeared at the site of inoculation till 48 HAI, whereas in non-transgenic ASD16 plants, a blanch lesion with a thin brown border was formed within 48 HAI (Fig. 6). These lesions slowly turned into grey
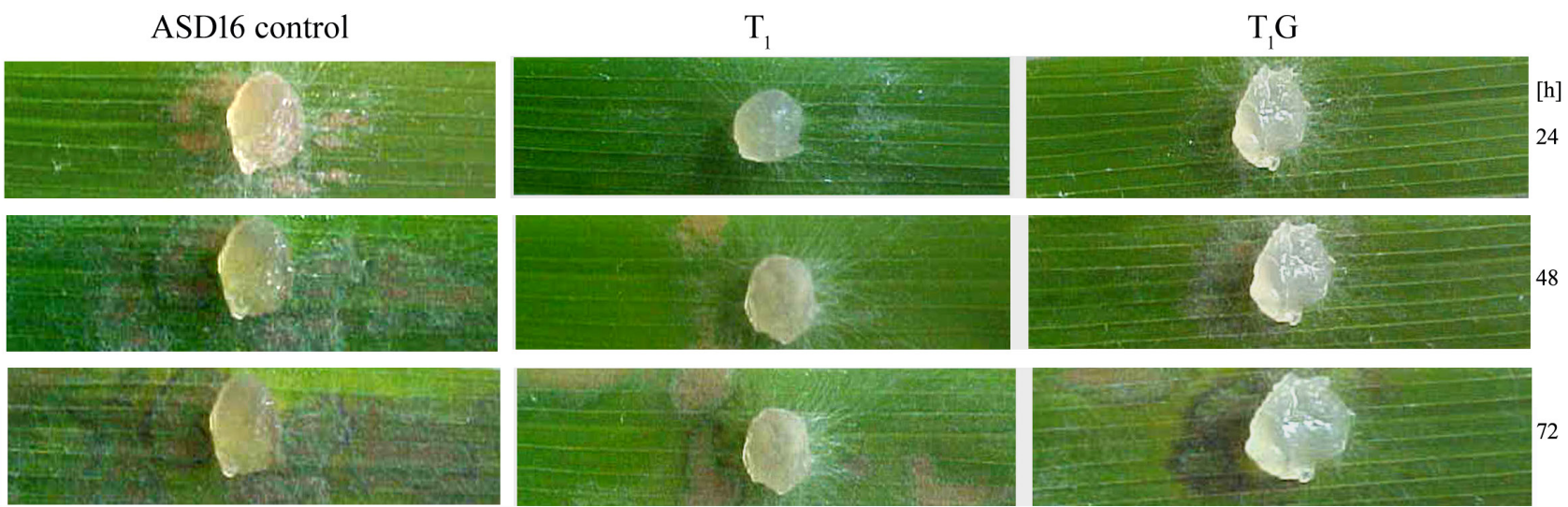

Fig. 5. Assessment of sheath blight resistance by detached leaf assay in the parental ASD16 line and its $\mathrm{F}_{2}$ progeny expressing tlp. 


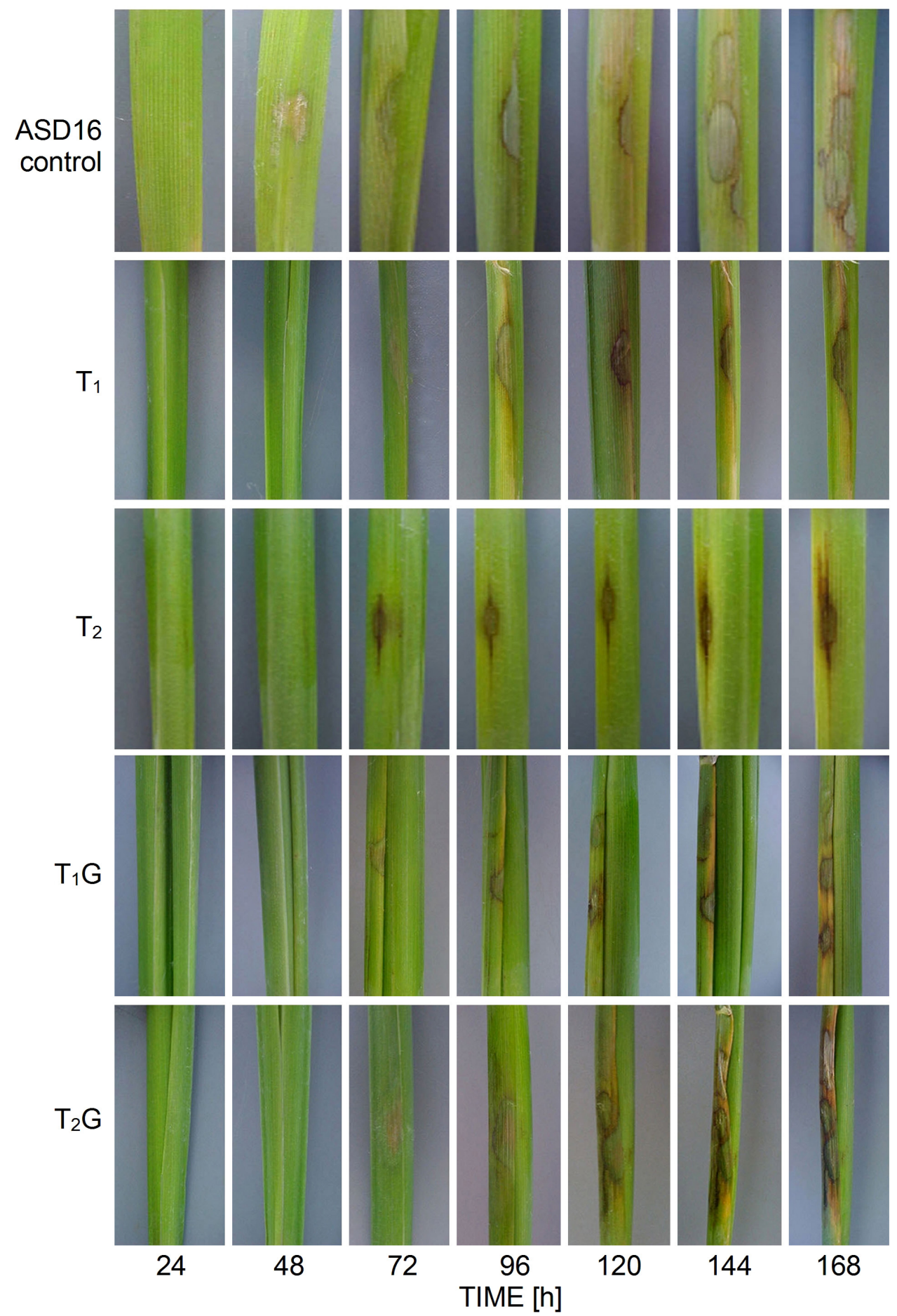

Fig. 6. Assessment of sheath blight resistance by intact leat sheath assay in the parental ASDl6 line and its $\mathrm{F}_{2}$ progeny expressing $t l p$.

and enlarged in size covering the entire leaf sheath within 168 HAI. Contrastingly, in all the transgenic parental lines $\left(\mathrm{T}_{1}\right.$ and $\left.\mathrm{T}_{2}\right)$ and their $\mathrm{F}_{2}$ lines expressing tlp, small brownish lesions appeared at $72 \mathrm{HAI}$, the lesion spread was very much restricted and an extensive browning of area surrounding the lesions were noticed (Fig. 6). In addition, the pathogen spread over the entire leaf sheaths, leading to complete drying of infected leaf sheath in non- transgenic plants within $168 \mathrm{HAI}$ and such a drying was absent in transgenic lines expressing tlp.

The HRLH of $\mathrm{T}_{1}, \mathrm{~T}_{2}, \mathrm{~T}_{1} \mathrm{G}$, and $\mathrm{T}_{2} \mathrm{G}$ was recorded as $2.34,2.66,2.15$, and $2.76 \%$ respectively, whereas it was $8.4 \%$ in control plants (Table 3 ). Total lesion spread on leaf sheath of the transgenic $\mathrm{F}_{2}$ line, $\mathrm{T}_{1} \mathrm{G}$ (expressing tlp and gna) after $168 \mathrm{~h}$ of inoculation was $4.47 \mathrm{~cm}$ as compared to $6.25 \mathrm{~cm}$ in $\mathrm{T}_{2} \mathrm{G}$ (expressing tlp and gna), while total lesion 


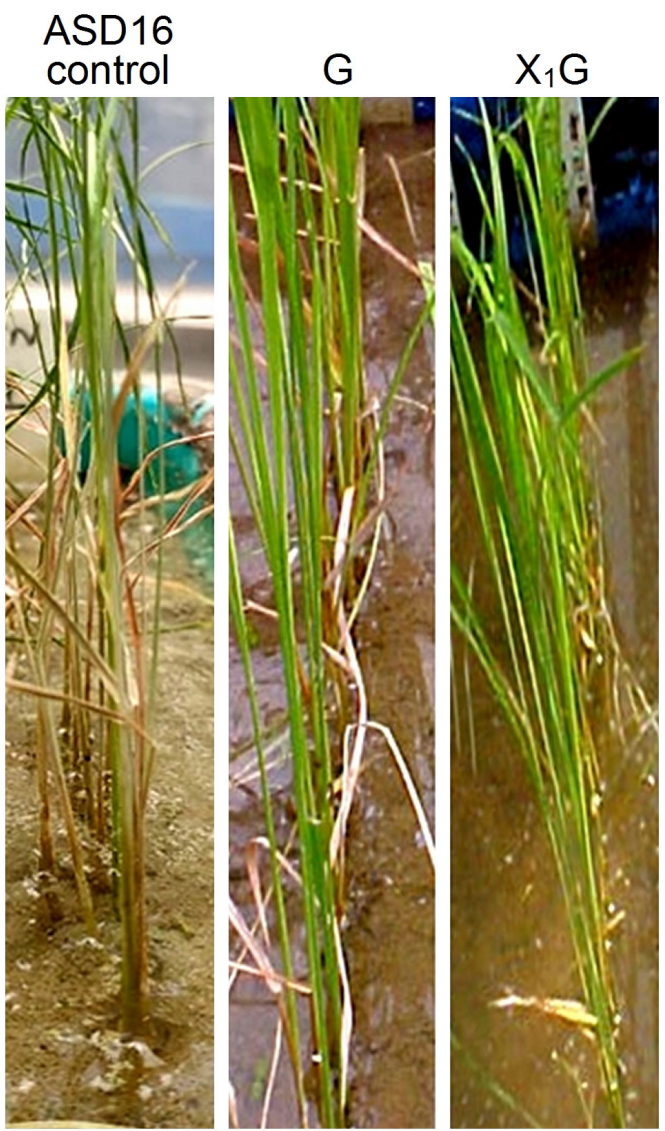

Fig. 7. Assessment of brown planthopper resistance by seedling box screening test in the parental ASD16 line and its $\mathrm{F}_{2}$ progeny expressing gna.

spread on non-transgenic ASD16 was $11.83 \mathrm{~cm}$ (Table 3). Similarly, the parental homozygous lines $T_{1}(4.91 \mathrm{~cm})$ and $\mathrm{T}_{2}(6.74 \mathrm{~cm})$ showed a significant reduction in the total lesion spread compared to control (Table 3 ).

A homozygous gna parental line, $\mathrm{G}$ and $\mathrm{F}_{2}$ progenies were evaluated for their resistance against BPH. First and second leaves with orange tips and slight stunting symptom initiated $3 \mathrm{~d}$ after insect release in non-transgenic ASD16 control and susceptible check (TN1). The similar type of symptom initiation in transgenic plants and resistant check PTB 33 was observed only on $6 \mathrm{~d}$ after the insect release. Severe stunting, drying, and mortality of seedlings in TN1 were noticed on $9 \mathrm{~d}$ after the insect release with a mean damage grade of 8.6 (Fig. 7, Table 4). The scoring was done only after TN1 exhibited more than $90 \%$ damage which normally noticed $9 \mathrm{~d}$ after the insect release. Of the transgenic lines and controls tested, PTB 33, the resistant check scored the lowest mean damage rating (2.80), while transgenic parental line and it's three $\mathrm{F}_{2}$ lines exhibited a damage rating between 4.4 and 4.9. The $\mathrm{F}_{2}$ lines, $\mathrm{X}_{1} \mathrm{G}, \mathrm{T}_{1} \mathrm{G}$, $\mathrm{X}_{2} \mathrm{G}$ and their parental line, $\mathrm{G}$ registered a mean damage rating of $4.4,4.7,4.8$, and 4.9 respectively. However, these mean damage rating were significantly lesser than in nontransgenic control which showed a mean damage rating of 7.7 (Table 4).

\section{Discussion}

Though the management of biotic constraints such as, BB, $\mathrm{ShB}$, and $\mathrm{BPH}$ has been achieved through use of synthetic pesticides, it is neither sustainable nor environmentally safe. An effective alternate to chemical control is the exploitation of host plant resistance. Developing biotic stress resistant crop cultivars through conventional breeding methods is time consuming. However, genetic engineering to develop insect and pathogen resistant lines as a part of plant breeding programme could overcome problems posed by conventional methods of controlling pest and diseases.

In the present study, we pyramided two transgenes in an elite indica rice cultivar ASD16 to develop lines expressing combinations of traits by conventional crossing of transgenic homozygous lines. Sexual hybridizations were performed in two different combinations in order to get two genes in a pyramided line. The pyramided $F_{2}$ lines showed enhanced protection against $\mathrm{BB}$ or $\mathrm{ShB}$ and BPH. Datta et al. (2002) pyramided three transgenes $X a 21, B t(c r y)$ and $R C 7$ chitinase in a single elite rice line by conventional crossing of two IR72 transgenic homozygous stable lines, one carrying the $\mathrm{Xa21}$ gene and the other carrying both $B t$ and rice chitinase $(R C 7)$ genes in order to incorporate multiple resistance against BB, $\mathrm{YSB}$, and $\mathrm{ShB}$. It is important to ensure that the transgenic parents used for gene pyramiding through sexual crossing are homozygous lines for the individual resistance genes. Datta et al. (2002) used stable homozygous IR72 lines of $X a 21$, rice chitinase $(R C 7)$, and $B t$ (cry) for sexual crossing. In our experiments, homozygous lines for BB, $\mathrm{ShB}$, and BPH resistance sources were used as parental lines in the hybridization programmes. Southern blot hybridization analyses demonstrated the presence of transgenes in parental lines as well as in $F_{2}$ progenies of all combinations.

Two transgenic lines, expressing $X a 21$ and their $\mathrm{F}_{2}$ derivatives exhibited resistance to Xoo with a lesion length of $<3.0 \mathrm{~cm}$, while non-transgenic ASD16 control was associated with a significantly higher lesion length of 17.07 cm. Wang et al. (1996) demonstrated resistance to multiple Xoo races in the transgenic lines harbouring Xa21. Tu et_al. (1998) observed a lesion length of $<3.1 \mathrm{~cm}$ in the BB-resistant plants and an Xa21 donor (IRBB21) whereas non-transgenic control plants exhibited lesion lengths of 13.3 to $20.3 \mathrm{~cm}$. Maruthasalam et al. (2007) reported similar spectrum of resistance in ASD16 (expressing Xa21) and Pusa Basmatil lines (expressing Xa21, chill, and tlp).

The ShB resistance in the homozygous parental lines and their $\mathrm{F}_{2}$ generations were evaluated using two functional expression assay systems (Kumar et al. 2003). Present study using detached leaves revealed that the leaves of transgenic plants exhibited characteristic browning around the lesions signifying effective restriction of pathogenic invasion. Rapid yellowing and drying observed in the leaves of non-transgenic control was absent in the transgenic plants. Moreover, the number of infection cushions formed on leaves was 
significantly lesser in transgenic lines expressing tlp and their $\mathrm{F}_{2}$ derivatives as compared to non-transgenic control. Similar kinds of results were obtained in detached leaf assays by earlier workers (Kumar et al. 2003, Kalpana et al. 2006, Maruthasalam et al. 2007, Rajesh et al. 2016).

In intact leaf sheath assay, a precocious browning at the site of inoculation was observed only in the transgenic plants and such a browning might play a major role in arresting the pathogen spread. In non-transgenic control plants, this browning was absent and drying of leaf sheaths was also noticed, while leaf sheaths of transgenic plants expressing tlp and their $\mathrm{F}_{2}$ derivatives remained green, despite $\mathrm{ShB}$ infection. This clearly demonstrated that the pathogen spread was very much restricted in transgenic lines possibly due to an extensive browning at the site inoculation, a defense response very similar to hypersensitive reaction. Groth and Nowick (1992) suggested that resistance to the spread of Rhizoctonia solani in rice could be consequent to production of oxidised phenolics (a dark zone around lesions). Maruthasalam et al. (2007) reported the same pattern of resistance in transgenic Pusa Basmati lines carrying the $t l p$ gene.

Transgenic ASD16 plants expressing tlp and their $\mathrm{F}_{2}$ lines recorded significantly lesser $\mathrm{HRLH} \%$ and total lesion spread as compared to control. There have been several reports of improved resistance of plants to diseases as a result of over expression of chitinases and TLPs (Brogue et al. 1991, Zhu et al. 1996, Lin et al. 1995, Datta et al. 1999, Datta et al. 2000). Lin et al. (1995) reported the development of lesions within 3-4 d after inoculation with $R$. solani on both non-transgenic and transgenic rice plants expressing rice chitinase (chi11) gene. However, the number and size of lesions in the transgenic plants were reported to be much smaller as compared to the control. The lesions invaded the upper half of the leaf sheaths in control plants, whereas in the transgenic plants the lesions were confined to the lower half. Datta et al. (1999) observed a mean sheath infection density of $8.2-19.1 \%$ in transgenic rice plants expressing TLP against $36.6 \%$ in control plants. In earlier reports, significantly lesser HRLH\% and total lesion spread in transgenic lines expressing chill and/or tlp were reported (Kumar et al. 2003, Kalpana et al. 2006, Maruthasalam et al. 2007). Recently, Rajesh et al. (2016) has demonstrated the inheritance of sheath blight resistance (upto $\mathrm{T}_{4}$ generation) in transgenic ASD16 rice plants expressing a chitinase gene.

In the standard seedling box method of BPH screening when all the seedlings of TN1 were completely killed, each seedling of the transgenic and non-transgenic lines were examined and given a score from 0 to 9 based on the damage level, following Xu (2013). The development of stunting symptom was noticed very slowly in transgenic plants compared to TN1 and non-transgenic ASD16 plants. The parental gna line and its four $\mathrm{F}_{2}$ derivatives exhibited moderately resistant reaction to BPH. Resistance rating was done only in the seedling stage, as varieties resistant at seedling stage were reported to be resistant at later stages of plant growth. This finding is in accordance with the report of Bharathi and Chelliah (1991). Rao et al. (1998) conducted BPH bioassays in transgenic rice plants expressing GNA and reported that expression of GNA in the transgenic plants resulted in reduction in survival and overall fecundity of the insects, retarded insect development and expressed a deterrent effect on BPH feeding. Maqbool et al. (2001) reported $25 \%$ reduction in the survival of the BPH in the pyramided lines expressing cry $1 A c, c r y 2 A$ and gna, in addition, observed a very slow rate of insect development on gna expressing plants as compared to non-transgenic plants. Myint et al. (2012) reported a higher mortality $(82.9 \%)$ of female $\mathrm{BPH}$ in preliminary pyramided lines of ADR52 rice harboring two $\mathrm{BPH}$ resistance gene loci, namely $\mathrm{BPH} 25$ and $\mathrm{BPH} 26$, whereas a lesser percentage (11.4-14.3\%) of female BPH mortality was recorded in preliminary near-isogenic ADR52 rice carrying either BPH25 or BPH26. Xu (2013) also got a similar kind of results for the pyramided japonica rice lines expressing $\mathrm{BPH}$ resistance genes, $\mathrm{BPH} 14$ and BPH15.

The present study reports a successful pyramiding of insect and disease resistance genes in ASD16, an indica rice cultivar. The pyramided lines exhibited resistance to economically important bacterial or fungal pathogen and an insect pest. The expressions of genes in the parental lines and the respective $\mathrm{F}_{2}$ lines were similar in terms of protection conferred by them. The pyramided lines that are identified in the present study could well be utilized in future breeding programmes which aim for enhanced resistance against $\mathrm{BPH}$ and diseases of rice.

\section{References}

Arunakumari, K., Durgarani, C.V., Satturu, V., Sarikonda, K.R., Chittoor, P.D.R., Vutukuri, B., Laha, G.S., Nelli, A.P.K., Gattu, S., Jamal, M., Prasadbabu, A., Hajira, S., Sundaram, R.M.: Marker assisted pyramiding of genes conferring resistance against bacterial blight and blast diseases into Indian rice variety MTU1010. - Rice Sci. 23: 306-316, 2016.

Balachiranjeevi, C.H., Naik, S.B., Kumar, V.A., Harika, G., Swamy, H.K.M., Hajira, S.K., Kumar, T.D., Anila, M., Kale, R.R., Yugender, A., Pranathi, K., Koushik, M.B.V.N., Suneetha, K., Bhadana, V.P., Hariprasad, A.S., Laha, G.S., Rekha, G., Balachandran, S.M., Madav, M.S., Senguttuvel, P., Fiyaz, A.R., Viraktamath, B.C., Giri, A., Swamy, B.P.M., Ali, J., Sundaram, R.M.: Marker-assisted pyramiding of two major, broad-spectrum bacterial bacterial blight resistance genes, $\mathrm{Xa} 21$ and $\mathrm{Xa33}$ into an elite maintainer line of rice, DRR17B. - Plos ONE 13: 1-16, 2018.

Baliyan, N., Mehta, K., Rani, R., Purushottum, Boora, K.S.: Evaluation of pyramided rice genotypes derived from cross between CSR-30 and IRBB-60 Basmati variety against bacterial leaf blight. - Vegetos Int. J. Plant Res. 29: 184-188, 2016.

Bharathi, M., Chelliah, S.: Genetics of rice resistance to brown planthopper and relative contribution of genes to resistance mechanisms. - Rice Genet. 2: 255-261, 1991.

Brogue, K., Chet, I., Holliday, M., Cressman, R., Biddle, P., Knowlton, S., Mauvais, C.J., Broglie, R.: Transgenic plants with enhanced resistance to the fungal pathogen Rhizoctonia solani. - Science 254: 1194-1197, 1991.

Czapla, T.H., Lang, B.A.: Effects of plant lectins on the larval development of European corn borer (Lepidoptera: Pyralidae) and southern corn rootworm (Coleoptera: Chysomelidae). - J. 
Econ. Entomol. 83: 2480-2485, 1990.

Datta, K., Baisakh, N., Thet, K.M, Tu, J., Datta, S.K.: Pyramiding transgenes for multiple resistance in rice against bacterial blight, yellow stem borer and sheath blight. - Theor. appl. Genet. 106: 1-8, 2002.

Datta, K., Koukolikova, N.Z., Baisakh, N., Oliva, N., Datta, S.K.: Agrobacterium-mediated engineering for sheath blight resistance of indica rice cultivars from different ecosystems. Theor. appl. Genet. 100: 832-839, 2000.

Datta, K., Velazhahan, R., Oliva, N., Ona, I., Mew, T., Khush, G.S., Muthukrishnan, S., Datta, S.K.: Over-expression of the cloned rice thaumatin-like protein $(P R-5)$ gene in transgenic rice plants enhances environmental friendly resistance to Rhizoctonia solani causing sheath blight disease. - Theor. appl. Genet. 98: 1138-1145, 1999.

Fukuoka, S., Saka, N., Mizukami, Y., Koga, H., Yamanouchi, U., Yoshioka, Y., Hayashi, N., Ebana, K., Mizobuchi, R., Yano, M.: Gene pyramiding enhances durable blast disease resistance in rice. - Sci. Rep. 5: 1-7, 2015.

Gomez, K.K., Gomez,A.A: Statistical Procedures for Agricultural Research. - Wiley and Sons, New York 1984.

Groth, D.E., Nowick, E.M.: Selection for resistance to rice sheath blight through number of infection cushions and lesion type. - Plant Dis. 76: 721-723, 1992.

Habibi, J., Backus, E.A., Czapla, T.H.: Plant lectins affect survival of the potato leafhopper (Homoptera: Cicadellidae). - J. Econ. Entomol. 86: 945-951, 1993.

Heinrichs, E.A., Mochida, A.: From secondary to major pest status: the case of insecticide induced rice brown planthopper, Nilaparvata lugens, resurgence. - Prot. Ecol. 1: 201-218, 1984.

Jiang, G.H., Xu, C.G., Tu, J.M., Li, X.H., He, Y.Q., Zhang, Q.F.: Pyramiding of insect and disease resistance genes into an elite indica, cytoplasm male sterile restorer line of rice, 'Minghui 63'. - Plant Breed. 123: 112-116, 2004.

Kalpana. K., Maruthasalam, S., Rajesh, T., Poovannan, K., Kumar, K.K., Kokiladevi, E., Raja, J.A.J., Sudhakar, D., Velazhahan, R., Samiyappan, R., Balasubramanian, P.: Engineering sheath blight resistance in elite indica rice cultivars using genes encoding defense proteins. - Plant Sci. 170: 203-215, 2006.

Kauffman, H.E., Reddy, A.P.K., Hsieh, S.P.Y., Merca, S.D.: An improved technique for evaluating resistance of rice varieties to Xanthomonas oryzae. - Plant Dis. Rep. 57: 537-541, 1973.

Khush, G.S., Bacalangco, E., Ogawa, T.: A new gene for resistance to bacterial blight from Oryza longistaminata. Rice Genet. Newslett. 7: 121-122, 1990.

Krishnamurthy, J., Samiyappan, R., Vidhyasekaran, P., Nakkeeran, S., Rajeswari, E., Raja, J.A.J., Balasubramanian, P.: Efficacy of Trichoderma chitinases against Rhizoctonia solani, the rice sheath blight pathogen. - J. Biosci. 24: 207213, 1999.

Kumar, K.K., Poovannan, K., Nandakumar, R., Thamilarasi, K., Geetha, C., Jayashree, N., Kokiladevi, E., Raja, J.A.J., Samiyappan, R., Sudhakar, D., Balasubramanian, P.: A high throughput functional expression assay system for a defence gene conferring transgenic resistance on rice against the sheath blight pathogen, Rhizoctonia solani. - Plant Sci. 165: 969-976, 2003.

Lin, W., Anuratha, C.S., Datta, K., Potrykus, I., Muthukrishnan, S., Datta, S.K.: Genetic engineering of rice for resistance to sheath blight. - Biotechnology 13: 686-691, 1995.

Maqbool, S.B., Riazuddin, S., Loc, N.T., Gatehouse, A.M.R., Gatehouse, J.A., Christou, P.: Expression of multiple insecticidal genes confers broad resistance against a range of different rice pests. - Mol. Breed. 7: 85-93, 2001.

Maruthasalam, S., Kalpana, K., Kumar, K.K., Loganathan, M.,
Poovannan, K., Raja, J.A.J., Kohiladevi, E., Samiyappan, R., Sudhakar, D., Balasubramanian, P.: Pyramiding transgenic resistance in elite indica rice cultivars against the sheath blight and bacterial blight. - Plant Cell Rep. 26: 791-804, 2007.

Mew, T.W., Vera Cruz, C.M. Variability of Xanthomonas oryzae: specificity in infection of rice differentials. - Phytopathology 69: 152-155, 1979.

Mohanty, S.: Trends in global rice consumption. - Rice Today 12: 44-45, 2013.

Myint, K.K.M., Fujita, D., Matsumura, M., Sonoda, T., Yoshimura, A., Yasui, H.: Mapping and pyramiding of two resistance genes for resistance to the brown planthopper (Nilaparvata lugens (Stal)) in the rice cultivar ADR32. Theor. appl. Genet. 124: 495-504, 2012.

Ou, S.H.: Rice diseases. II Ed. - Commonwealth Mycological Institute, Kew 1985.

Powell, K.S., Gatehouse, A.M.R., Hilder, V.A., Gatehouse, J.A.: Antimetabolic effects of plant lectins and plant and fungal enzymes on the nymphal stages of two important rice pests, Nilaparvata lugens and Nephotettix cinciteps. - Entomol. Exp. Appl. 66: 119-126, 1993.

Powell, K.S., Gatehouse, A.M.R., Hilder, V.A., Gatehouse, J.A.: Antifeedant effects of plant lectins and an enzyme on the adult stage of the rice brown planthopper, Nilaparvata lugens. Entomol. Exp. Appl. 75: 51-59, 1995.

Rajesh, T., Maruthasalam, S., Kalpana, K., Poovannan, K., Kumar, K.K., Kokiladevi, E., Sudhakar, D., Samiyappan, R., Balasubramanian, P.: Stability of sheath blight resistance in transgenic ASD16 rice lines expressing a rice chill gene encoding chitinase. - Biol. Plant. 60: 749-756, 2016.

Rao, K.V., Rathore, K.S., Hodges, T.K., Fu, X., Stoger, E., Sudhakar, D., Williams, S., Christou, P., Bharathi, M., Bown, D.P., Powell, K.S., Spence, J., Gatehouse, A.M.R., Gatehouse, J.A.: Expression of snowdrop lectin (GNA) in transgenic rice plants confers resistance to rice brown planthopper. - Plant J. 15: 469-477, 1998.

Rebmann, G., Mauch, F., Dudler, R.: Sequences of a wheat cDNA encoding a pathogen-induced thaumatin-like protein. - Plant mol. Biol. 17: 283-290, 1991.

Roberts, W.K., Selitrennikoff, C.P.: Zeamatin, an antifungal protein from maize with membrane-permeabilizing activity. - J. gen. Microbiol. 136: 1771-1778, 1990.

Ronald, P.C., Albano, B., Tabien, R., Abenes, L., Wu, K., McCouch, S.R., Tanksley, S.D.: Genetic and physical analysis of the rice bacterial blight disease resistance locus, Xa21. Mol. Genet. Genom. 236: 113-120, 1992.

Savary, S., Willocquet, L., Elazegui, F.A., Castilla, N.P., Teng, P.S.: Rice pest constraints in tropical Asia: quantification of yield losses due to rice pests in a range of production situations. - Plant Dis. 84: 357-369, 2000.

Sehgal, O.P., Reiger, R., Mohamed, F.: Induction of bean PR4d-type protein in divergent plant species after infection with tobacco ring spot virus and its relationship with tobacco PR-5. - Phytopathology 81: 215-219, 1991.

Tu, J., Datta, K., Khush, G.S., Zhang, Q., Datta, S.K.: Field performance of Xa21 transgenic indica rice (Oryza sativa L.), IR72. - Theor. appl. Genet. 101:15-20, 2000.

Tu, J., Ona, I., Zhang, Q., Mew, T.W., Khush, G.S., Datta, S.K.: Transgenic rice variety IR72 with Xa21 is resistant to bacterial blight. - Theor. appl. Genet. 97: 31-36, 1998.

Velazhahan, R., Chen-Cole, K., Anuratha, C.S., Muthukrishnan, S.: Induction of thaumatin-like proteins (TLPs) in Rhizoctonia solani infected rice and characterization of two new cDNA clones. - Physiol. Plant. 102: 21-28, 1998.

Vigers, A.J., Roberts, W.K., Selitrennikoff, C.P.: A new family of plant antifungal proteins. - Mol. Plant-Microbe Interact. 4: 
315-321, 1991

Wang, G.L., Song, W.Y., Ruan, D.L., Sideris, S., Ronald, P.C.: The cloned gene Xa21 confers resistance to multiple Xanthomonas oryzae pv. oryzae isolates in transgenic plants. - Mol. Plant-Microbe Interact. 9: 850-855, 1996.

Wei, Y., Yao, F., Zhu, C., Jiang, M., Li, G., Song, Y., Wen, F.: Breeding of transgenic rice restorer line for multiple resistance against bacterial blight, striped stem borer and herbicide. Euphytica 163: 177-184, 2008.

$\mathrm{Xu}, \mathrm{J} .:$ Pyramiding of two BPH resistance genes and $S t v-b^{i}$ gene using marker-assisted selection in japonica rice. - Crop Breed. appl. Biotechnol. 13: 99-106, 2013.
Yasuda, N., Mitsunaga, T., Hayashi, K., Koizumi, S., Fujita, Y.: Effects of pyramiding quantitative resistance genes Pi21, Pi34 and Pi35 on rice leaf blast disease. - Plant Dis. 99: 904-909, 2015.

Zhai, W., Wang, W., Zhou, Y., Li, X., Zheng, X., Zhang, Q., Wang, G., Zhu, L.: Breeding bacterial blight-resistant hybrid rice with the cloned bacterial blight resistance gene Xa21. Mol. Breed. 8: 285-293, 2001.

Zhu, B., Chen, T.H.H., Li, P.H.: Analysis of late-blight disease resistance and freezing tolerance in transgenic potato plants expressing sense and antisense genes for an osmotin-like protein. - Planta 198: 70-77, 1996. 